\title{
Protein disulphide isomerase-assisted functionalization of keratin-based matrices
}

\author{
Margarida M. Fernandes • Andreia C. Gomes • Andreia Vasconcelos • \\ Florentina-Daniela Munteanu • Tzanko Tzanov • Maria Sameiro T. Gonçalves • \\ Nicole End • Kai-Uwe Schoening • Georg M. Guebitz • Artur Cavaco-Paulo
}

Received: 3 November 2010 / Revised: 14 February 2011 / Accepted: 20 February 2011 /Published online: 19 March 2011

(C) Springer-Verlag 2011

\begin{abstract}
In living systems, protein disulphide isomerase (PDI, EC 5.3.4.1) regulates the formation of new disulphide bonds in proteins (oxidase activity) and catalyzes the rearrangement of non-native disulphide bonds (isomerase activity), leading proteins towards their native configuration. In this study, PDI was used to attach cysteine-containing compounds (CCCs) onto hair, to enhance compound migration within hair fibre and to trigger protein release. A fluorescent (5(6)-TAMRA)-labelled keratin peptide was incorporated into hair by using PDI. Similarly, PDI promoted the grafting of a cysteine-functionalized dye onto wool, as suggested by matrix-assisted laser desorption and ionization time-of-flight results. These reactions were thought to involve oxidation of disulphide bonds between CCCs and wool or hair cysteine residues, catalyzed by the oxidized
\end{abstract}

M. M. Fernandes $\cdot$ A. Vasconcelos $\cdot$ A. Cavaco-Paulo $(\bowtie)$

Center of Textile Engineering, University of Minho,

Campus of Azurém,

4800-058 Guimarães, Portugal

e-mail: artur@det.uminho.pt

\section{A. C. Gomes}

Department of Biology, Centre of Molecular and Environmental Biology (CBMA), Campus of Gualtar, University of Minho, 4710-057 Braga, Portugal

\section{F.-D. Munteanu}

Faculty of Food Engineering, Tourism and Environmental

Protection, University Aurel Vlaicu of Arad,

No. 2,

310330 Arad, Romania

\section{T. Tzanov}

Group of Molecular and Industrial Biotechnology, EUETIT,

Technical University of Catalonia,

Colom 1,

8222 Terrassa Barcelona, Spain
PDI active site. On the other hand, PDI was demonstrated to enhance the migration of a disulphide bondfunctionalized dye within the keratin matrix and trigger the release of RNase A from wool fibres' surface. These observations may indicate that an isomerisation reaction occurred, catalyzed by the reduced PDI active site, to achieve the thiol-disulphide exchange, i.e. the rearrangement of disulphide bonds between CCCs and keratin. The present communication aims to highlight promising biotechnological applications of PDI, derived from its almost unique properties within the isomerase family.

Keywords Cysteine-containing compounds (CCCs) . Disulphide bonds $\cdot$ Keratin fibres $\cdot$ Protein disulphide isomerase $(\mathrm{PDI}) \cdot$ Protein release

M. S. T. Gonçalves

Department of Chemistry,

Campus of Gualtar, University of Minho,

4710-057 Braga, Portugal

N. End $\cdot$ K.-U. Schoening

Ciba Inc. (part of BASF),

WRO-1059.6.14,

4002 Basel, Switzerland

G. M. Guebitz

Department of Environmental Biotechnology,

Graz University of Technology,

Graz, Austria 


\section{Introduction}

In vivo, correct protein folding is catalyzed by the enzyme protein disulphide isomerase (PDI, E.C. 5.3.4.1). This multifunctional eukaryotic oxidoreductase is structurally characterized by the presence of functional thioredoxin-like domains which are responsible for its catalytic properties (Appenzeller-Herzog and Ellgaard 2008; Wilkinson and Gilbert 2004). PDI was first known as the catalyst of native disulphide bond formation from cysteine residues in the refolding of Ribonuclease A (RNase A) (Goldberger et al. 1963). Since then, several studies emphasized PDI as catalyst for reduction, oxidation and isomerisation in a wide range of cysteine-containing substrates (Kersteen et al. 2005; Walker et al. 1996; Xiao et al. 2005), where the type of reaction catalyzed is determined by the redox state of the PDI active site (Lyles and Gilbert 1991). Thus, apart from its natural function of protein refolding, PDI could potentially catalyze the functionalization of cysteine-rich protein fibres using various functional cysteine-containing molecules.

Keratin is the basic building block of the complex morphological structure of human and animal hair fibres and constitutes an example of such cysteine-rich protein fibres. Their cysteine content varies from $7 \%$ to $20 \%$ of total amino acid residues, creating a stable disulphide bond (cystine) network (Wilson and Lewis 1927). Such high content of cystine suggests that keratin fibres should be susceptible to modification with enzymes that are active towards disulphide bonds and more specifically with PDI.

Several patents report on modification of keratin fibres using PDI for applications such as the restoration of original properties of harshly treated wool textiles (King and Brockway 1989), or for styling and colouring of human hair under mild conditions (Huang et al. 2008; Richardson et al. 1996; Green et al. 2001). However, the ability of PDI to catalyze incorporation of functional molecules onto keratinous substrates has not been reported so far.

Many current cosmetic hair treatments are based on the disulphide bond modulation, which alter many hair properties resulting on damage to the hair fibre (Schueller and Romanowski 1998; Wolfram 2003; Gray 2001; Bolduc and Shapiro 2001; Dawber 1996). The reversible and relatively stable nature of the disulphide bonds in keratin fibres (Block et al. 1939) makes them a good target for functionalization, as an alternative to chemical agents commonly used in cosmetics, or to take advantage of the strong linkage that can be created between hair and a cysteine-containing functional molecule.

The high content of cysteine on keratinous fibres explains the stability of the fibre macrostructure, imparting those fibres' good mechanical, thermal and chemical properties (Wilson and Lewis 1927; Wysocki et al. 1954; Block et al. 1939). For this reason, keratin fibres are continuously being reported as novel biocompatible materials in the area of tissue engineering. Keratins can be isolated from human or animal hair by controlling the conditions which lead to disulphide bonds scission and reformation and further fabricated into various designs, such as films, microcapsules and sponges (Vasconcelos et al. 2008; Katoh et al. 2004; Sierpinski et al. 2008; Tachibana et al. 2005; Morgan et al. 2007; Tanabe et al. 2004). Therefore, the keratins' disulphide bonds are also thought to be ideal targets for the development of enzymatic systems for drug delivery. In fact, the versatility of disulphide bonds has been proposed as a general strategy for designing drug delivery systems (Saito et al. 2003). However, an approach based on PDI as an external switchon agent for drug release has not been reported so far.

This study aims to broaden the application spectra of disulphide-rich keratinous fibres using enzymatic approaches. Three different PDI-assisted controlled reactions are described:

1. PDI-assisted incorporation of different cysteinecontaining compounds (CCCs; a dye and a peptide) into hair and wool substrates in order to generate milder methods to dye hair with longer lasting colour by creating new disulphide bonds between hair and peptide

2. PDI-assisted promotion of the migration of CCCs (dyes), previously attached to keratin, along hair fibres, to avoid repetitive hair dyeing procedures.

3. PDI-induced controlled release of a CCC protein (e.g. reduced form of RNase A) from wool matrices, as a new approach for drug release methodology.

\section{Materials and methods}

\section{Materials}

Enzymes Stock solutions of PDI from bovine liver (Sigma) and Ribonuclease A from bovine pancreas (Sigma) were prepared in phosphate buffer $\mathrm{pH} 7.5$ in the concentrations of 0.05 and $1.5 \mathrm{~g} / \mathrm{L}$, respectively. The alkaline protease Esperase (E.C.3.4.21.62), a subtilisin with a broad specificity, was supplied by Novozyme and prepared in Tris- $\mathrm{HCl}$ buffer $\mathrm{pH} 8.5$.

Keratins Natural European human hair samples were provided by International Hair Importers \& Products Inc. (New York) and prior to peptide treatment, two different pre treatments were performed. In one pre-treatment, the hair tresses were previously subjected to a washing procedure 
with a commercial shampoo. In the other pre-treatment, the hair was treated with ethanol $(1: 20 w / v)$ for $2 \mathrm{~h}$ to remove the external lipids followed by a reducing treatment in the presence of $0.01 \mathrm{M}$ dithiothreitol (DTT) in Tris- $\mathrm{HCl}$ buffer $0.1 \mathrm{M} \mathrm{pH} 7.5$, in a bath ratio of 1:100 for $1 \mathrm{~h}$. The reduction treatment was made to make the thiol groups available in hair for further PDI application. Woven 100\% merino wool fabrics were provided by Albano Antunes Morgado Lda (Portugal). The wool fabrics were washed with $1 \mathrm{~g} / \mathrm{L}$ nonionic surfactant Lutensol AT-25 (BASF, Germany) at $0.1 \mathrm{M}$ $\mathrm{Na}_{2} \mathrm{CO}_{3} / \mathrm{NaHCO}_{3}$ buffer $\mathrm{pH} 9.0,40^{\circ} \mathrm{C}$ for $30 \mathrm{~min}$ in a RotaWash laboratory machine (MKII Series 7227, Shirley Developments Ltd) at liquor to material ratio 20:1, and subsequently in distilled water and air-dried, prior to experiments.

Dyes The cysteine-containing dyeing agents were provided by Ciba Specialty Chemicals (Switzerland). Figure 1 shows the structure of the dyes. Dye A contains one cysteine residue in reduced form and a chromophoric group attached to the amino group of the dye. Dye B contains two cysteine moieties oxidized to form a disulphide bridge and the chromophoric group, in this case, is attached through the carboxilic group. The stock solution of each dye (1.25 mM) was prepared in $0.1 \mathrm{M}$ phosphate buffer $\mathrm{pH}$ 7.5.

Peptide A keratin peptide (KP) was specially designed for this work and thus synthesized by JPT Peptide Technologies GmbH (Germany). The peptide was developed based on the aminoacid sequence of cuticular keratin type II from human hair (Naeem et al. 2006) and possesses a sequence with 13 amino acids comprising two cysteine residues (TAMRA$\mathrm{X}_{3} \mathrm{CX}_{4} \mathrm{CX}_{2}-\mathrm{CONH}_{2}$ ) with a molecular weight of $1,600 \mathrm{~g} / \mathrm{mol}$.

The peptide was covalently linked by its N-terminal to a fluorescent dye 5(6)-carboxytetramethyl-rhodamine, succi-

Fig. 1 Structure of the cysteinecontaining dyes<smiles>O=C(O)C(CS)Nc1ccc([N+](=O)[O-])cc1[N+](=O)[O-]</smiles>

nimidyl ester (5(6)-TAMRA), $\lambda_{\mathrm{ex}}=544 \mathrm{~nm}$ and $\lambda_{\mathrm{em}}=$ $572 \mathrm{~nm}$, to facilitate analysis of the peptide penetration into keratin substrates. Stock solutions of $1 \mathrm{mg} / \mathrm{mL}$ were prepared in $0.1 \mathrm{M}$ Tris- $\mathrm{HCl}$ buffer, $\mathrm{pH}$ 7.5.

Methods

PDI-assisted incorporation of cysteine-containing peptide on hair

Hair treatment with the peptide Hair samples (100 mg), both reduced and washed hair, were treated with $3 \mathrm{~mL} 0.1 \mathrm{M}$ Tris$\mathrm{HCl}$ buffer $\mathrm{pH} 7.5$ containing $200 \mu \mathrm{L}$ of PDI stock solution and $600 \mu \mathrm{L}$ of peptide stock solution, at $37^{\circ} \mathrm{C}$ in a bath with orbital agitation, $100 \mathrm{rpm}$ for $1 \mathrm{~h}$. After treatment, the hair samples were washed with commercial shampoo and under running water. As control, the hair was treated in the same way, omitting the peptide in the solution.

Fluorescence microscopy on hair cross-sections The influence of PDI on peptide application was visualized by fluorescence microscopy on hair transversal cuts. The treated hair fibres were embedded into an epoxy resin and transversal cuts with $15 \mu \mathrm{m}$ were prepared using a microtome (Microtome Leitz). Three cross-sections per sample were made and analyzed on a Leica Microsystems DM-5000B epifluorescence microscope with appropriate filter settings using $\times 40$ objective. Images were acquired with a Leica DCF350FX digital camera and processed with LAS AF Leica Microsystems software. The fluorescence images were taken at same excitation conditions: the same filter was used for all the images collected as well as the brightness, time of exposure and gain. The most representative images of different hair cross-sections of the same hair sample were chosen.<smiles></smiles>

Dye B 
Colour variation The colour variation was measured directly from the hair-peptide solution before and after the treatment, at $555 \mathrm{~nm}$. Since the colour of the solution comes from the peptide, from the differences in absorbance, the quantity of peptide that penetrates/attach into the hair was determined and expressed as colour variation. The percentage of colour variation was calculated based on Eq. 1.

ColourVariation $(\%)=\frac{\mathrm{Abs}_{\text {initial }}-\mathrm{Abs}_{\text {final }}}{\mathrm{Abs}_{\text {initial }}}$

Zeta potential The zeta potential values of the peptide solutions were measured by photon-correlation spectroscopy (PCS) using a Malvern zetasizer NS (Malvern Instruments) at $25.0 \pm 0.1^{\circ} \mathrm{C}$. The instrument was routinely calibrated with a $\pm 66 \mathrm{mV}$ latex standard.

PDI-assisted incorporation of a cysteine-containing dye on wool

Wool coloration experiments Wool samples (0.25 g each) were dyed at $20^{\circ} \mathrm{C}$ in Ahiba Spectradye dyeing apparatus (Datacolor Int.) with bath containing $10 \mathrm{~mL} 0.1 \mathrm{M}$ Tris$\mathrm{HCl}$ pH 7.5 buffer, $300 \mu \mathrm{L}$ of the dye A stock solution (Dye A, Fig. 1) and $20 \mu \mathrm{L}$ of the PDI stock solution. After dyeing, all samples were washed extensively to remove the non-covalently bound dye using Lutensol AT-25 in a Rota-Wash machine, bath ratio $100: 1$, at $50^{\circ} \mathrm{C}$, for 45 min according to BS 1006: $1990 \mathrm{CO}_{2}$ (LiakopoulouKyriakides et al. 1998). The washing was repeated until complete removal of the unfixed dye.

Hydrolysis of wool samples Hydrolysis of the wool samples (dyed and un-dyed) was performed after PDIassisted dyeing prior to matrix-assisted laser desorption and ionization time-of-flight (MALDI-TOF) analysis. The treatment was carried out in a thermostated laboratory shaker at $100 \mathrm{rpm}$ in liquor ratio 100:1 in the case of pretreatment and 150:1 in the case of hydrolysis after dyeing. Ten milligrams of sample were treated with $7 \mathrm{U} / \mathrm{mL}$ Esperase (native form). The treatment was performed in $0.1 \mathrm{M}$ Tris- $\mathrm{HCl}$ buffer, $\mathrm{pH} 8.5$, at $37^{\circ} \mathrm{C}$ for $24 \mathrm{~h}$.

MALDI-TOF mass spectroscopy Digested dyed wool samples were analyzed by MALDI-TOF mass spectrometer (Thermo BioAnalysis MALDI-TOF DYNAMO system) equipped with a pulsed nitrogen laser $(332 \mathrm{~nm}, 2 \mathrm{~ns}$ pulse width) and Dynamic Extraction (a method for optimizing the extraction and acceleration of ions from the sample) in negative ion reflector mode, using DHB (2,5-dihydrobenzoic acid) as matrix solution. A $1.5 \mu \mathrm{l}$ sample was mixed with $5 \mu \mathrm{l}$ of cyano-4-hydroxycinnamic acid diluted (1:1) with 50:50 acetonitrile/nanopure water. Then, $1.5 \mu \mathrm{l}$ of the resulting mixture was spotted on the stainless steel MALDI target and dried.

PDI-assisted migration of the cysteine-containing dye on hair Hair samples (150 mg; UNA-Europ. Natural hair, colour white bleached from Fishbach\&Miller) were dyed with or without PDI in a dye bath composed of $10 \mathrm{~mL}$ of $0.1 \mathrm{M}$ Tris- $\mathrm{HCl} \mathrm{pH} 7.5$ buffer, $300 \mu \mathrm{L}$ of the dye B stock solution (Dye B, Fig. 1) and $20 \mu \mathrm{L}$ of the PDI stock solution. The hair samples were only partially dyed to be possible to observe the colour migration on the un-dyed parts. The dyeing experiments were carried out in the Ahiba Spectradye dyeing apparatus (Datacolor Int.) at $20^{\circ} \mathrm{C}$, $\mathrm{pH}$ 8.0, for $50 \mathrm{~min}$. After dyeing, all hair samples were washed extensively to remove the unfixed dye in a RotaWash machine (MKII Series 7227, Shirley Developments Limited) using commercial shampoo at $50^{\circ} \mathrm{C}$ during $45 \mathrm{~min}$ according to BS 1006: $1990 \mathrm{CO}_{2}$ (Liakopoulou-Kyriakides et al. 1998) immediately after the dyeing procedure. The hair samples were dried at room temperature.

For the migration tests, the dyed hair was treated with a PDI formulation $(0.05 \mathrm{~g} / \mathrm{L})$, containing a redox buffer GSH/GSSG ( $1 \mathrm{mM} \mathrm{GSH,} 0.2 \mathrm{mM} \mathrm{GSSG}, \Delta E=-260 \mathrm{mV}$ ) to set the redox state of the PDI active site to the reduced form, in an Ahiba Spectradye dyeing apparatus at $20^{\circ} \mathrm{C}$,

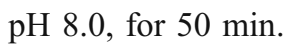

PDI-assisted controlled release of a cysteine-containing protein from wool

Incorporation of RNase A on wool In order to incorporate RNase A into a keratin matrix, both the protein and the wool samples were reduced prior to the oxidation attachment. The wool samples were reduced in $0.1 \mathrm{M}$ Tris- $\mathrm{HCl}$ buffer $\mathrm{pH} 7.5$, in the presence of $50 \mathrm{mM}$ DTT and $3 \mathrm{M}$ guanidine hydrochloride $(\mathrm{GndHCl}$; wool to liquid ratio $1: 20)$, at $37^{\circ} \mathrm{C}$ for $2 \mathrm{~h}$. After reduction, the wool fabrics were extensively washed with tap water and $0.1 \mathrm{M}$ citric acid/ $\mathrm{Na}_{2} \mathrm{HPO}_{4} \cdot 2 \mathrm{H}_{2} \mathrm{O}$ buffer, $\mathrm{pH} 4.0$ to prevent its reoxidation by air oxygen. The reduction of RNase A was performed according to Lyles and Gilbert (1991) in the presence of DTT and GndHCl. The oxidation (attachment) of the reduced RNase A $(1.50 \mathrm{mg} / \mathrm{mL})$ into the reduced wool (50 mg) was assessed in the presence of an oxidation buffer ( $2 \mathrm{mM}$ GSH, $10 \mathrm{mM} \mathrm{GSSG}, \Delta E=-228 \mathrm{mV}$ ) in $0.1 \mathrm{M}$ Tris$\mathrm{HCl}$ buffer $\mathrm{pH}$ 7.5. The reduced wool was incubated with $50 \mu \mathrm{M}$ reduced RNase A solution overnight at $25^{\circ} \mathrm{C}$ in a shaker bath at $90 \mathrm{rpm}$, in presence of redox buffer in order to promote its oxidation. The samples were then immersed in a washing buffer $(0.1 \mathrm{M}$ Tris- $\mathrm{HCl}$ buffer, $\mathrm{pH} 7.5)$ until no 
more protein was released (measured by Lowry method). For control, samples prepared by the same procedure using phosphate buffer ( $\mathrm{pH} 7.5$ ) were used.

PDI induced release of RNase A from wool The release of RNase A from wool surface was enzymatically catalyzed by using PDI, based on its ability to catalyze the isomerisation of disulphide bonds on misfolded proteins. The PDI was incubated for $25 \mathrm{~min}$ in GSH/GSSG buffer (1 mM $\mathrm{GSH}, 0.2 \mathrm{mM}$ GSSG, $\Delta E=-260 \mathrm{mV}$ ) to set the redox state of the PDI active site (reduced form) to be able to isomerise the disulphide bonds between wool fabric and RNase A. The wool fabric with incorporated RNase A was immersed in $0.22 \mu \mathrm{M}$ PDI in GSH/GSSG buffer for $1 \mathrm{~h}$, in a shaker bath at room temperature. The biological activity of RNase A and protein release was assessed at different time points. For control, the RNase-treated wool was incubated in the same buffer omitting PDI.

RNase A activity assay The RNase A biological activity was assayed based on the PDI oxidative folding of RNase A (Lyles and Gilbert 1991). RNase A activity was determined spectrophotometrically at $25^{\circ} \mathrm{C}$ using cytidine $2^{\prime}: 3^{\prime}$-cyclic monophosphate (cCMP) as a substrate (Spencer and Raffa 2004). Assay mixtures were composed of $0.1 \mathrm{M}$ Tris- $\mathrm{HCl}$ buffer, $\mathrm{pH}$ 7.5, $4.5 \mathrm{mM}$ cCMP and $250 \mu \mathrm{L}$ of released RNase A from sample solution. The reaction was followed at $296 \mathrm{~nm}$ in a quartz cuvette of $0.1 \mathrm{~cm}$ path length.

The slope, i.e. linear increase in absorbency, was determined and activity was calculated using Eq. 1, using Beer Law, where $\varepsilon$ is the substrate molar extinction coefficient $\left(190 \mathrm{M}^{-1} \mathrm{~cm}^{-1}\right)$.

Activity. $\mathrm{L}^{-1}=$ Slope $\times V_{\text {Total }} \times \frac{1}{\varepsilon} \times \frac{1}{V_{\text {Sample }}} \times 10^{3}$

Protein determination The total protein concentration was determined by a modification of the micro Lowry method (Lowry et al. 1951) using bovine serum albumin as standard and using Sigma test kit no. P 5656, measured at $750 \mathrm{~nm}$.

FITC linkage to RNase A To enable to study the RNase A incorporation onto wool fabrics and the release in the presence of PDI, fluorescein 5(6)-isothiocyanate (FITC) was linked to the protein. A volume of $2 \mathrm{~mL}$ of a solution of $2 \mathrm{mg} / \mathrm{mL}$ of RNase A protein in a sodium carbonate buffer, pH 9.0 was incubated with $100 \mu \mathrm{L}$ of a $1 \mathrm{~g} / \mathrm{L}$ FITC solution at RT for $2 \mathrm{~h}$. Unbound FITC was separated from the conjugate by passing the mixture through a desalting column PD10. The ratio of fluorescence to protein (Molar $\mathrm{F} / \mathrm{P}=0.79$ ) was calculated in order to determine labelling efficiency. The estimated value was within the ideal limits (0.3-1.0) indicating efficient labelling.

Fluorescence microscopy on wool cross-sections Two different wool samples were analyzed by fluorescence microscopy: wool fabric incorporated with FITC-RNase A and wool fabric incorporated with FITC-RNase A followed by the treatment with PDI in the refolding buffer. Therefore, several fibres of each sample were embedded into the epoxy resin and transversal cuts of the fibres with $15 \mu \mathrm{m}$ were prepared using a microtome (Microtome Leitz). The fluorescence microscopy images were taken using the same conditions of the method for the analysis of hair fibre crosssections, above mentioned. The most representative images among all were chosen.

\section{Results}

The peptide and dyes used in this study were engineered as PDI substrates, i.e. cysteine residues were introduced. Two dyes with general formulas R-SH and R-S-S-R' (Fig. 1) containing cysteine and cystine, respectively, and the peptide (KP) comprising two cysteine residues, linked to a fluorescent dye, were synthesized. A keratin intermediate filaments protein was chosen for the KP development. The amino acid sequence of the keratin type II cuticular $\mathrm{Hb} 5$, a protein that in humans is encoded by the KRT85 gene (Rogers et al. 1997; Koehn et al. 2010), was chosen ${ }^{1}$ and a fragment of 13 amino acids comprising two cysteines separated by four different amino acids was then selected and chemically synthesized.

PDI-assisted incorporation of cysteine-containing peptide on hair

In order to predict the affinity of a peptide towards the hair surface, two important properties should be highlighted: the peptide size (molecular weight) and the isoelectric point (pI). The smaller is the peptide, the higher the expected penetration on the scaled structure of hair. Small peptides such as $\mathrm{KP}\left(M_{\mathrm{w}} \sim 1,600 \mathrm{~g} / \mathrm{mol}\right)$ are expected to penetrate deep into the scaled structure of the fibre. However, the KP uptake was not as high as expected (Fig. 2). This low affinity can be explained based on peptide pI which was found to be 5.2 . $^{2}$ Thus, KP acquires negative charge at $\mathrm{pH}$

\footnotetext{
${ }^{1}$ Gene information available on Pubmed at www.ncbi.nlm.nih.gov/ gene/53622

2 Calculated with "Peptide Property Calculater" available at www. innovagen.se
} 


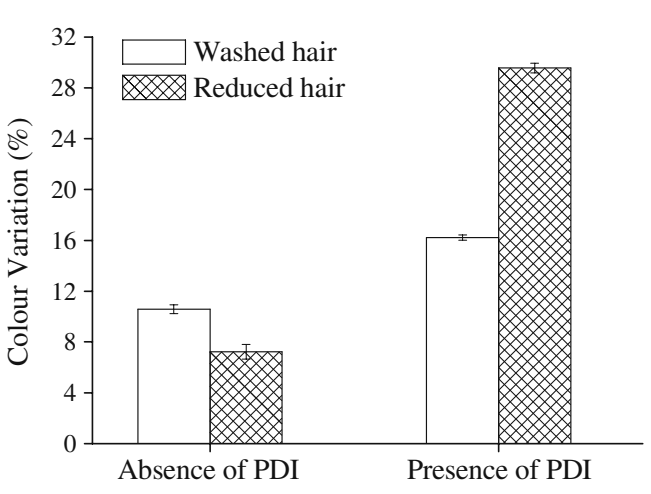

Fig. 2 KP uptake on both reduced and washed hair in the absence and presence of PDI, determined by colour variation method

higher than its $\mathrm{pI}$, as proved by PCS $(-14.06 \pm 2.33 \mathrm{mV})$. Such negative charges decrease the specificity towards negatively charged membranes, such as those found in hair. Human hair has an isoelectric point near 3.7 (Wilkerson 1935; Regismond et al. 1999) which explains the negative surface charges under most $\mathrm{pH}$ conditions. These electrostatic interactions are believed to play a determining role in the adsorption mechanism, which might explain the low affinity of the KP towards hair, despite its size.

Colour variation is proportional to peptide uptake by hair; thus, it could be observed that KP adsorption into hair fibres was favoured by the presence of PDI (Fig. 2). However, this increase was more pronounced with previously reduced hair, where KP uptake was $30 \%$, while in washed hair, an uptake of $16 \%$ was observed. The reduction treatment results in higher quantity of free thiol groups in hair, and further application of PDI increased the affinity of peptide towards hair. The absence of PDI, on the other hand, results in poor peptide adsorption.

Fluorescence microscopy on hair cross-sections, after the washing procedures, was performed to visualize the presence of the peptide, which is linked to a fluorescent dye (5(6)-TAMRA), and the effect of PDI on its penetration. The hair without peptide treatment is depicted in Fig. 3a. It can be seen that the hair without the peptide treatment, does not possess auto fluorescence. By comparing all the hair cross-section images subjected to the same excitation conditions of brightness, time of exposure and gain, it can be seen that PDI treatment seems to favour the penetration of KP inside the fibres' cortex (Fig. 3b) while the hair samples treated in the same conditions but without PDI show the presence of peptide at the cuticle (Fig. 3c). Spectrophotometric measurements are in agreement with these findings, since $\mathrm{KP}$ uptake is more efficient in the presence of PDI ( $\sim 16 \%$ for washed hair and $30 \%$ for reduced hair) than without PDI $(\sim 10 \%$ for washed hair and $8 \%$ for reduced hair; Fig. 2).

These results suggest that PDI might promote the creation of new disulphide bonds between the used cysteine-containing peptide and hair. Furthermore, as KP is based on the amino acid sequence of human hair, it is thought that PDI, acting as chaperone and folding enzyme (Wang and Tsou 1998), may contribute to a conformational change of KP towards its minimum free energy and thus facilitating penetration inside the fibre's cortex.

\section{PDI-assisted incorporation of cysteine-containing dye} on wool

In order to confirm the ability of PDI to catalyze the CCC disulphide bonding to the keratinous substrates, the approach used to study the incorporation of KP on hair was similarly applied to the incorporation of a cysteine containing dye on wool.

The quantification of disulphide bonds is important for gaining a comprehensive understanding of the chemical structure of a protein (Gorman et al. 1997), which in this case could be used to predict dye-fibre interactions. To confirm $\mathrm{CCC}$ bonding to keratinous fibres (dye-fibre interactions), a protease (subtilisin A) digestion of wool dyed in the presence and absence of PDI was performed. The hydrolysate obtained from the enzymatic digestion was then analyzed by MALDI-TOF mass spectrometry. The enzyme used in this work, subtilisin A, is a non-specific protease that preferably attacks neutral and acidic amino acids. Hence, it is expected that the enzyme will promote the rupture of most of the peptide bonds on dyed wool.

Two major fragments, with peaks around $m / z 254$ and $\mathrm{m} / \mathrm{z} 397$ were detected in the hydrolysate of wool dyed in absence of PDI (Table 1). The peak at $\mathrm{m} / \mathrm{z} 254$ is thought to be assigned to dye A, because it fits with the corresponding theoretical molecular weight $\left(M_{\mathrm{w}}=\right.$
Fig. 3 Fluorescence images of cross-sections of reduced human hair fibres, at $\times 40$ magnifications; a control (reduced hair fibres); b reduced hair fibres treated with KP and $\mathbf{c}$ reduced hair fibres treated with KP in the presence of PDI

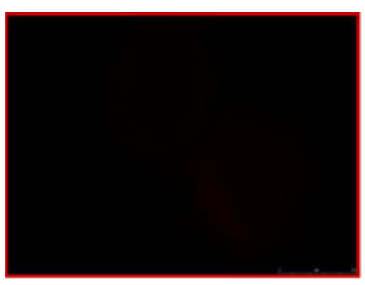

A

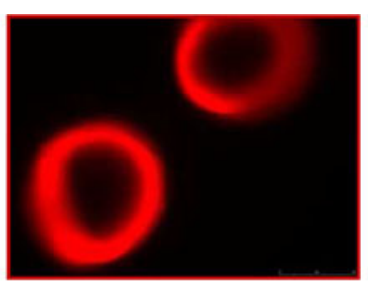

B

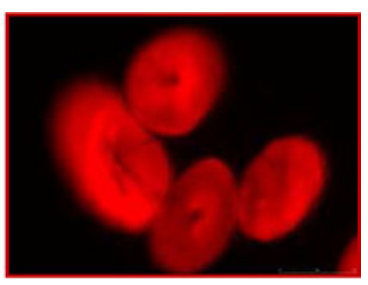

$\mathrm{C}$ 
$254.166 \mathrm{~g} / \mathrm{mol}$ ), after losing a SH group. This adduct can be a result of the complete enzymatic hydrolysis of the peptide-like bonds between dye and wool. The other peak was attributed to the fragment composed by the dye A (that loses a $\mathrm{NO}_{2}$ group) linked to arginine residue from wool (Table 1). Dye A (Fig. 1) possesses a reactive carboxyl group $(-\mathrm{COOH})$ that, during the dyeing process without PDI, may react with the available amino moiety from basic amino acids such as histidine, arginin and lysine in wool, creating a new peptide-like bond. The peak at $m / z 397$ that was attributed to a fragment consisting of the dye attached to an arginine residue is in good agreement with this statement.

When the dyeing of wool is made in the presence of PDI, the thiol group from the dye A structure is thought to be more reactive than the carboxyl group and may react with cysteine moiety in wool, favouring the creation of disulphide bonds. In the spectra of the hydrolysate obtained after enzymatic digestion of the PDI-assisted dyed wool the single peak correspondent to the dye disappeared and higher molecular weight peaks appeared around $m / z 450$ and $m / z$ 464, suggesting the occurrence of these disulphide bonding (Table 1). Disulphide bonds originated from PDI-catalyzed reactions between dye and wool are strong and stable linkages (Gilbert and Lester 1995) that are not subjected to protease hydrolysis. Therefore, it may be deduced that the peaks represent fragments of the dye linked by disulphide bonds to cysteine that, in its turn, is linked to another amino acid residue, giving rise to higher molecular weight adducts. The first peak (at around $m / z$ 450) was thought to be due to the dye A (that loses carboxyl group) bounded to a cysteine-serine fragment digested from wool, while the second peak $(\mathrm{m} / \mathrm{z} 464)$ might correspond to the dye A (that also loses carboxyl group) bounded to a cysteinethreonine fragment from wool (Table 1).

These results suggest that PDI might be able to promote the formation of new disulphide bonds on wool. It should be noted that the sequence of the possible assignments shown in Table 1 results from the study of the most probable combination of amino acids with the dye A, based on its molecular structure and molecular weight.
PDI-assisted migration of a cysteine-containing dye on hair

As an attempt to reduce hair dyeing intervals, the potential of PDI to enhance migration of a cysteine-containing dye (dye B, Fig. 1) was investigated. Consequently, hair samples were only partially dyed so that the central part of the hair remained un-dyed. The un-dyed width was $2.5 \mathrm{~cm}$. The hair was washed and dried, and then PDI in the redox buffer was applied.

A tendency of dye migration towards the middle (un-dyed) part of the hair was observed (Fig. 4). The treatment with PDI was able to reduce the extent of the un-dyed area from 2.5 to $0.5 \mathrm{~cm}$ in length.

These results indicate the potential of the PDI to promote the migration of the attached CCCs over keratinous surfaces. A possible isomerisation mechanism for migration, both scission and reformation of the disulphide bonds previously created between the hair and the dye, is suggested.

PDI-assisted controlled release of a cysteine-containing protein from wool

The isomerisation mechanism that PDI catalyse is also thought to be involved in the release mechanism of a protein, namely RNase A previously attached to the wool surface. In this step, PDI was applied to manipulate the scission of the disulphide bonds created between the cysteine residues of a keratin matrix and those of a CCC, acting, therefore, as a switch-on agent for protein release.

Besides the fact that RNase A contains four disulphide bonds in its native state, it is also one of the classic model systems used in protein science (Chang 1999; Juminaga et al. 1998). Before the application of PDI, RNase A protein was attached to the wool surface via disulphide bonds. The results suggest that in an oxidizing environment, by the application of a glutathione-containing buffer (equilibrium mixture of Lglutathione reduced (GSH) and L-glutathione oxidized (GSSG)), concomitant oxidation of cysteines from reduced RNase A and wool takes place. Thus, consequent formation of new disulphide bonds between the fibre and the RNase A may occur, resulting in covalent
Table 1 List of measured and theoretical (calculated) masses and corresponding structures of adduct obtained by MALDITOF of wool dyed with dye A, in the presence and absence of PDI, after hydrolysis by protease

\begin{tabular}{|c|c|c|c|}
\hline & \multicolumn{2}{|c|}{ Molar mass (g/mol) } & \multirow[t]{2}{*}{ Possible corresponding structure } \\
\hline & Observed & Theoretical & \\
\hline \multirow[t]{2}{*}{ Absence of PDI } & 254.381 & 254.166 & Dye A(-SH) \\
\hline & 396.880 & 397.414 & Dye $\mathrm{A}\left(-\mathrm{NO}_{2}\right)+\mathrm{Arg}$ \\
\hline \multirow[t]{2}{*}{ Presence of PDI } & 450.262 & 449.441 & Dye $\mathrm{A}\left(-\mathrm{CO}_{2} \mathrm{H}\right)+\mathrm{Cys}+\mathrm{Ser}\left(-\mathrm{H}_{2} \mathrm{O}-\mathrm{H}_{2}\right)$ \\
\hline & 464.199 & 463.471 & Dye $\mathrm{A}\left(-\mathrm{CO}_{2} \mathrm{H}\right)+\mathrm{Cys}+\operatorname{Thr}\left(-\mathrm{H}_{2} \mathrm{O}-\mathrm{H}_{2}\right)$ \\
\hline
\end{tabular}


Fig. 4 PDI-assisted migration of the dye $\mathrm{B}$ on hair

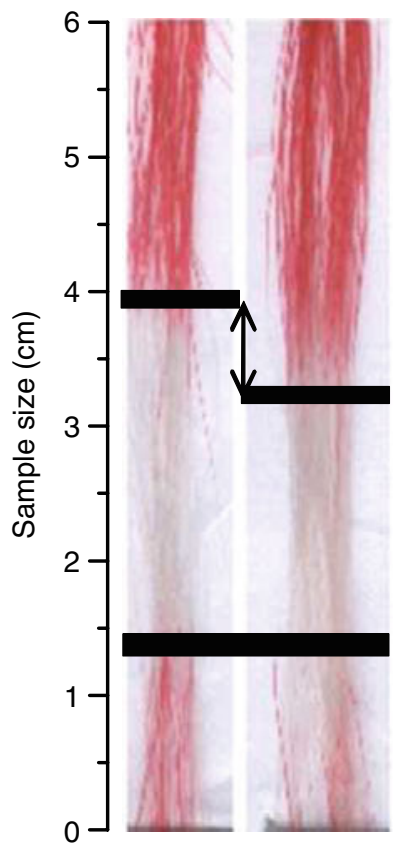

protein fixation. A simplified cysteine oxidation in GSSG is shown in Scheme 1.

The reduction potential created $(\mathrm{GSH}=2 \mathrm{mM}$; $\mathrm{GSSG}=$ $10 \mathrm{mM}$ ) was $\Delta E=-228 \mathrm{mV}$, is higher than the reduction potential of cysteine residues $(E=-340 \mathrm{mV})$ and allows the formation of disulphide bonds between wool and RNase A. Measurements of the remaining protein content in the solution after the treatment and washing procedures revealed up to $90 \%$ of the RNase A attached to the surface.

To corroborate these findings, incorporation of the RNase A on wool was visualized by fluorescence microscopy on wool. To do so, RNase A was conjugated with a fluorescent dye-FITC, with a ratio of fluorescence to protein (Molar F/P) of 0.79. The crosssections of the wool fabrics treated with RNase A-FITC conjugate in the presence of glutathione buffer showed a brighter layer when compared to control treated in phosphate buffer, indicating that this protein is indeed attached to wool surface in above mentioned conditions (Fig. 5).

PDI was then used to release the previously attached RNase A from the wool fabrics. The measurement of catalytic activity and protein content in solution after PDI application revealed its ability to release the protein from the wool surface and to assess the percentage of protein that is in active form.

$$
2 \text { Cysteine }(-\mathrm{SH})+\mathrm{GSSG} \rightarrow 2 \mathrm{GSH}+\mathrm{Cystine}(\mathrm{S}-\mathrm{S})
$$

Scheme 1 Oxidation of two cysteine residues promoted by oxidized GSSG

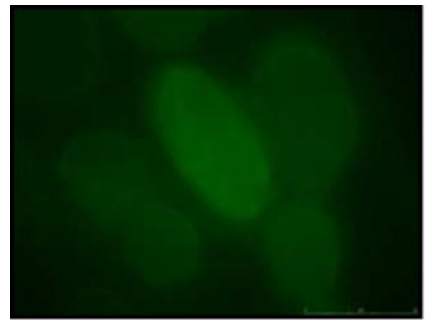

A

Fig. 5 Fluorescence microscopy images of fibre cross-sections of reduced wool yarns treated with FITC-labelled RNase A in phosphate buffer (a) and in presence of glutathione-containing buffer (b)

The activity of the released protein was measured based on the oxidative refolding mechanism of RNase A in the presence of its substrate, cCMP. Increase in absorbance at $296 \mathrm{~nm}$ was monitored for 5 min after incubation of the RNase-treated wool with the PDI for $1 \mathrm{~h}$. The higher activity observed after PDI application suggests that RNase A is released in its active form from the wool surface (Fig. 6). The protein content measurements suggest about $40 \%$ release of the protein attached to the fibre after PDI application. During the PDI treatment, small amounts of keratin were also released from wool, and these values were subtracted from the RNase A contents. The activity of the released RNase A was $46 \%$ of that of native protein, when same protein contents compared (Table 2).

The results obtained indicate the possibility to link RNase A to the wool surface in oxidative conditions, while PDI is able to induce its release, thus acting as a switch-on agent to release the protein. The activity loss of the release protein was roughly half of that of native state.

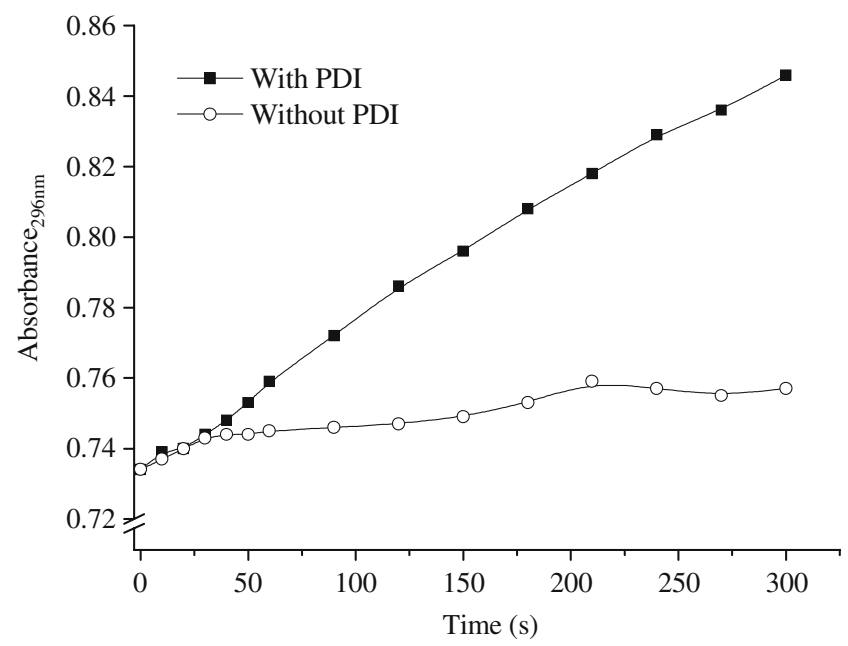

Fig. 6 RNase A activity in solution, after being released from the wool surface 
Table 2 RNase A activity and protein content released from wool fabric

\begin{tabular}{llll}
\hline Conditions & Activity $(\mathrm{U} / \mathrm{mL})$ & $\begin{array}{l}\text { RNase A } \\
\text { released } \\
(\mathrm{mg} / \mathrm{mL})\end{array}$ & $\begin{array}{l}\text { Percentage of } \\
\text { recovery (\%), } \\
\text { compared to } \\
\text { native enzyme }\end{array}$ \\
\hline Without PDI & $0.32 \pm 0.04$ & $0.020 \pm 0.019$ & 15.77 \\
With PDI & $1.53 \pm 0.02$ & $0.068 \pm 0.007$ & 45.45 \\
\hline
\end{tabular}

\section{Discussion}

The development of enzymatic methods for the functionalization of keratinous fibres may find many applications, from fibres dyeing to chemical compound delivery. One possible approach is to take advantage of the presence of disulphide bonds, a covalent linkage characterized by its reversible and yet relatively stable nature (Gilbert and Lester 1995).

A novel strategy for functionalization of keratinous fibres based on the ability of PDI to catalyze formation and scission of disulphide bonds between substrates and functional molecules has been developed in this study. Figure 7 illustrates the mechanistic background of PDI reactions exploited for keratin functionalization. The figure illustrates two possible reactions based on the state of PDI active site. When the active site is in its oxidized form, PDI catalysis formation of disulphide bonds and CCCs are, therefore, incorporated on to keratins. The release of the CCCs (disulphide scission), however, demands the PDI active site in its reduced form.

PDI was demonstrated to promote the covalent attachment of a cysteine-containing peptide on to reduced and washed hair. The reducing treatment, however, promoted higher yield of KP attachment probably due to the higher number of thiol groups created. Apart from being a suitable substrate for PDI because of its two cysteine residues, KP is thought to have affinity towards hair's surface. This low molecular weight peptide is a fragment of a protein encoded by the KRT85 gene, which is a keratin type II cuticular protein (Rogers et al. 1997; Koehn et al. 2010) and may be able to restore damaged cuticle parts. Also, as a type II $\alpha$-keratin, it might possess resilient yet pliable characteristics (Coulombe et al. 2004) that could be translated to the peptide and, therefore, to the hair fibre.
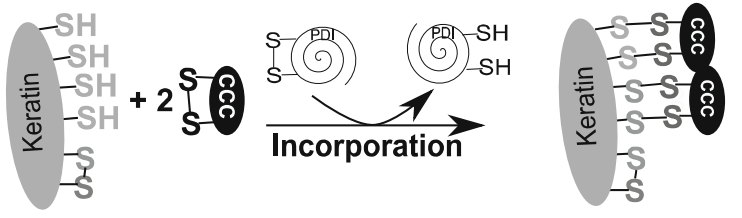

The attachment of a CCC on to hair in presence of PDI as presented may constitute an alternative, milder method for hair dyeing that promotes a long lasting colouring of hair while it may simultaneously increase the fibre robustness (Cavaco-Paulo and Silva 2007). Up to now, most of the many innovative treatments available are very aggressive to the hair fibre (Zviak and Milléquant 2005; Bhushan 2008). Therefore, a peptide that is able to form disulphide bonds with hair and penetrate into its cortex creates new perspectives for cosmetic industry.

Using the same approach as for studying the incorporation of KP into hair, the PDI-assisted incorporation of the cysteine containing dye on wool was also investigated. In this case, MALDI-TOF analysis was performed after a protease digestion of wool to evaluate the presence of disulphide bonds. Simplicity of sample preparation, rapid spectrum acquisition, high sensitivity and relative tolerance to impurities make MALDI-TOF attractive for analysis of small molecule analytes (Munteanu et al. 2008). Other authors have previously reported the use of MALDI-TOF in textile substrates. In some studies (Soltzberg et al. 2007), dyes and pigments with molecular masses between 200 and 1,100 Da have been identified while in others (ChromáKeull et al. 2000) this technique was used to identify reactive dyes and to monitor their hydrolysis. Moreover, the analysis of proteolysis products by MALDI-TOF has been reported to prove the existence of the disulphide arrangement (Gorman et al. 1997). Herein, MALDI-TOF study of the wool samples after incorporation of the dye in presence and absence of PDI suggested that disulphide bonds could be involved in the dye's attachment to the keratin substrate.

Central to the explanation of these two phenomena is the oxidized form of PDI active site, which promotes incorporation of CCCs into keratin substrates (Fig. 7). PDI-catalyzed disulphide formation occurs when oxidizing equivalents are transferred from the disulphide in the PDI active site (oxidized state) to the substrate (Ferrari and Söling 1999), as depicted in Fig. 7. Thus, in appropriate conditions, when the PDI active site is in oxidized form (as used in the study), it is possible to link CCCs onto keratinous fibres.

On the other hand, PDI was shown to promote the isomerisation (cleavage and reformation) of the disulphide bonds formed between the keratin substrate and the cysteine containing dye or protein (namely RNase A),

Fig. 7 Schematic illustration of the PDI-assisted reactions of CCCs on keratins 
resulting in migration of it along hair fibre or protein release, respectively.

In theory, the PDI isomerisation phenomenon requires one reactive thiol in the active site of PDI, thus in its reduced form (Hawkins et al. 1991). To transform the PDI active site on the reduced form the application of redox environment with a potential of $\Delta E=-260 \mathrm{mV}$ by the presence of equilibrium concentrations of $\mathrm{GSH}=1 \mathrm{mM}$ and $\mathrm{GSSG}=0.2 \mathrm{mM}$ is necessary. These conditions have been reported as optimal for promoting the renaturation of RNase A by an isomerisation mechanism (Lyles and Gilbert 1991). Nucleophilic attack of the PDI's thiol group (reduced form) on a previously formed disulphide bond between $\mathrm{CCC}$ and keratin is thought to result in the formation of a mixed disulphide intermediate between enzyme and substrate (keratin). If keratin has another available cysteine that can displace PDI, an isomerisation will occur through intramolecular rearrangement (Kersteen et al. 2005) and the CCC, previously released from keratin because of the PDI modulation of the disulphide bonds, will reattach to another available cysteine in keratin. The colour migration can thus be explained as a result of the displacement of CCC (dye) from one disulphide bond to another allowing its interaction along the keratin substrate (Fig. 7).

In the case of protein release from wool, as explained for the migration experiment, the reduced active site of PDI can function as a nucleophile and attack the disulphide bonds previously formed between protein and wool. After the formation of the complex between PDI and keratin, the CCC (RNase A) is released, and in this case, the RNase A cannot be reattached to the keratin substrate probably due to its higher molecular weight $\left(M_{\mathrm{w}}\right)$, which results in release of this protein.

The first disulphide linkage-employing drug conjugate that exploits the reversible nature of this unique covalent bond was recently approved for human use (Saito et al. 2003). For that reason, an increasing number of drug formulations that incorporate disulphide bonds have been developed (Gosselin et al. 2001; Ishida et al. 2001; Kakizawa et al. 2001; King et al. 1978; McKenzie et al. 2000). The results obtained in this study show the potential of PDI to be used in enzymatic systems which act as switches for protein release. Indeed, any active substance which is incorporated to the keratinous platform using disulphide bond modulation can be released in such way. Interestingly, this system can be applied to medical textiles with previously fixed drugs in order to more efficiently deliver the necessary pharmacological compounds.

This work paves the way for promising biotechnological applications of keratin substrates, such as human hair and wool, whose characteristics can be modified in a controlled manner by PDI treatments. These materials, enriched in disulphide bonds, were functionalized in order to develop novel applications for cosmetic and biomedical research.

The capacity of PDI to recognize different substrates in vitro, such as keratin substrates and tested peptides is of major importance since most literature reports only in vivo recognition.

Acknowledgment We thank to $F C T$ "Fundação para a Ciência e Tecnologia" (scholarship SFRH/BD/38363/2007) for providing Margarida Fernandes the grant for $\mathrm{PhD}$ studies.

\section{References}

Appenzeller-Herzog C, Ellgaard L (2008) The human PDI family: Versatility packed into a single fold. BBA-Mol Cell Res 1783 (4):535-548

Bhushan B (2008) Nanoscale characterization of human hair and hairconditioners. Prog Mater Sci 53(4):585-710

Block RJ, Diana B, Brand FC, Arnold S (1939) The Composition of keratins. The amino acid composition of hair, wool, horn, and other eukeratins. J Biol Chem 128(1):181-186

Bolduc C, Shapiro J (2001) Hair care products: waving, straightening, conditioning, and coloring. Clin Dermatol 19(4):431-436

Cavaco-Paulo AM, Silva CJSM (2007) Formulation containing neck domains and/or carbohydrate recognition domains for cosmetic applications, namely for the treatment of keratin fibres like hair. Portugal Patent WO/2007/136286, 29.11.2007

Chang J-Y (1999) Quantitative analysis of the composition of the native and scrambled ribonuclease A. Anal Biochem 268(1):147-150

Chromá-Keull H, Havlis J, Havel J (2000) Reactive dye Ostazine Black $\mathrm{V}-\mathrm{B}$ : determination in the dye-bath and hydrolysis monitoring by matrix-assisted laser desorption/ionisation time-of-flight mass spectrometry. Rapid Commun Mass Spectrom 14:40-43

Coulombe PA, Tong X, Mazzalupo S, Wang Z, Wong P (2004) Great promises yet to be fulfilled: Defining keratin intermediate filament function in vivo. Eur J Cell Biol 83(11-12):735-746

Dawber R (1996) Hair: Its structure and response to cosmetic preparations. Clin Dermatol 14(1):105-112

Ferrari DM, Söling HD (1999) The protein disulphide-isomerase family: unravelling a string of folds. Biochem J 339:1-10

Gilbert HF, Lester P (1995) Thiol/disulphide exchange equilibria and disulphide bond stability. Method Enzymol 251:8-28

Goldberger RF, Epstein CJ, Anfinsen CB (1963) Acceleration of reactivation of reduced bovine pancreatic ribonuclease by a microsomal system from rat liver. J Biol Chem 238(2):628-635

Gorman JJ, Ferguson BL, Speelman D, Mills J (1997) Determination of the disulphide bond arrangement of human respiratory syncytial virus attachment $(\mathrm{G})$ protein by matrix-assisted laser desorption/ionization time-of-flight mass spectrometry. Protein Sci 6(6):1308-1315

Gosselin MA, Guo W, Lee RJ (2001) Efficient gene transfer using reversibly cross-linked low molecular weight polyethylenimine. Bioconjug Chem 12(6):989-994. doi:10.1021/bc0100455

Gray J (2001) Hair care and hair care products. Clin Dermatol 19 (2):227-236

Green H, Corey GD, Compton BJ, Dijan P (2001) Attaching agents to tissue with transglutaminase and a transglutaminase substrate. US Patent 6267957, 01/20/1999

Hawkins H, Blackburn E, Freedman R (1991) Comparison of the activities of protein disulphide-isomerase and thioredoxin in catalysing disulphide isomerization in a protein substrate. Biochem J 275(349):53 
Huang X, Kobos RK, XU G (2008) Peptide-based carbon nanotube hair colorants and their use in hair colorant and cosmetic compositions. US Patent WO/2005/117537, 13.04.2005

Ishida T, Kirchmeier MJ, Moase EH, Zalipsky S, Allen TM (2001) Targeted delivery and triggered release of liposomal doxorubicin enhances cytotoxicity against human B lymphoma cells. BBABiomembranes 1515(2):144-158

Juminaga D, Wedemeyer WJ, Scheraga HA (1998) Proline isomerization in bovine pancreatic ribonuclease A. 1. Unfolding conditions. Biochemistry-US 37(33):11614-11620

Kakizawa Y, Harada A, Kataoka K (2001) Glutathione-sensitive stabilization of block copolymer micelles composed of antisense DNA and thiolated poly(ethylene glycol)-block-poly(L-lysine): a potential carrier for systemic delivery of antisense DNA. Biomacromolecules 2(2):491-497. doi:10.1021/bm0001421

Katoh K, Tanabe T, Yamauchi K (2004) Novel approach to fabricate keratin sponge scaffolds with controlled pore size and porosity. Biomaterials 25(18):4255-4262

Kersteen EA, Barrows SR, Raines RT (2005) Catalysis of protein disulphide bond isomerization in a homogeneous substrate. Biochemistry-US 44(36):12168-12178

King RD, Brockway BE (1989) Treatment of wool materials. United Kingdom Patent EP0276547, 11/04/1987

King T, Li Y, Kochoumian L (1978) Preparation of protein conjugates via intermolecular disulphide bond formation. Biochemistry 18 (17):1499-1506

Koehn H, Clerens S, Deb-Choudhury S, Morton JD, Dyer JM, Plowman JE (2010) The proteome of the wool cuticle. J Proteome Res 9(6):2920-2928. doi:10.1021/pr901106m

Liakopoulou-Kyriakides M, Tsatsaroni E, Laderos P, Georgiadou K (1998) Dyeing of cotton and wool fibres with pigments from Crocus sativus-Effect of enzymatic treatment. Dyes Pigm 36 (3):215-221

Lowry OH, Rosebrough NJ, Farr AL, Randall RJ (1951) Protein measurement with the folin phenol reagent. J Biol Chem 193 (1):265-275

Lyles MM, Gilbert HF (1991) Catalysis of the oxidative folding of ribonuclease A by protein disulphide isomerase: dependence of the rate on the composition of the redox buffer. Biochemistry-US 30(3):613-619

McKenzie DL, Kwok KY, Rice KG (2000) A potent new class of reductively activated peptide gene delivery agents. J Biol Chem 275(14):9970-9977. doi:10.1074/jbc.275.14.9970

Morgan ES, Havelka OK, Lochhead YR (2007) Cosmetic nanotechnology: polymers and colloids in cosmetics; ACS Symposium Series 961, vol 961. American Chemical Society, Washington DC

Munteanu F-D, Dinca N, Cavaco-Paulo A (2008) MALDI-TOF mass spectrometry in textile industry. In: Popescu C, Zamfir AD, Dinca N (eds) Applications of mass spectrometry in life safety. NATO Science for Peace and Security Series A: Chemistry and Biology. Springer, Dordrecht, pp 193-203

Naeem M, Wajid M, Lee K, Leal SM, Ahmad W (2006) A mutation in the hair matrix and cuticle keratin KRTHB5 gene causes ectodermal dysplasia of hair and nail type. J Med Genet 43 (3):274-279. doi:10.1136/jmg.2005.033381

Regismond STA, Heng Y-M, Goddard ED, FoM W (1999) Fluorescence microscopy observation of the adsorption onto hair of a fluorescently labeled cationic cellulose ether. Langmuir 15 (8):3007-3010. doi:10.1021/la9811665

Richardson K, Schilling M, Pocalyko J, Bailey L (1996) Covalent bonding of active agents to skin, hair or nails. United States Patent 5490980, 09/28/1994

Rogers MA, Winter H, Schweizer J, Langbein L, Praetzel S, Moll I, Krieg T (1997) Sequences and differential expression of three novel human type-II hair keratins. Differentiation 61(3):187-194

Saito G, Swanson JA, Lee K-D (2003) Drug delivery strategy utilizing conjugation via reversible disulphide linkages: role and site of cellular reducing activities. Adv Drug Deliver Rev 55(2):199215

Schueller R, Romanowski P (1998) The science of reactive hair-care products. Cosmet Toiletries 113:39-44

Sierpinski P, Garrett J, Ma J, Apel P, Klorig D, Smith T, Koman LA, Atala A, Van Dyke M (2008) The use of keratin biomaterials derived from human hair for the promotion of rapid regeneration of peripheral nerves. Biomaterials 29(1):118-128

Soltzberg LJ, Hagar A, Kridaratikorn S, Mattson A, Newman R (2007) MALDI-TOF Mass spectrometric identification of dyes and pigments. J Am Soc Mass Spectrom 18(11):2001-2006

Spencer SD, Raffa RB (2004) Isothermal titration calorimetric study of RNase-A kinetics (cCMP $\rightarrow 3$ '-CMP) involving end-product inhibition. Pharm Res 21(9):1642-1647. doi:10.1023/B: PHAM.0000041460.78128.0f

Tachibana A, Kaneko S, Tanabe T, Yamauchi K (2005) Rapid fabrication of keratin-hydroxyapatite hybrid sponges toward osteoblast cultivation and differentiation. Biomaterials 26(3):297-302

Tanabe T, Okitsu N, Yamauchi K (2004) Fabrication and characterization of chemically crosslinked keratin films. Mater Sci Eng C 24(3):441-446

Vasconcelos A, Freddi G, Cavaco-Paulo A (2008) Biodegradable materials based on silk fibroin and keratin. Biomacromolecules 9 (4):1299-1305

Walker KW, Lyles MM, Gilbert HF (1996) Catalysis of oxidative protein folding by mutants of protein disulphide isomerase with a single active-site cysteine. Biochemistry-US 35(6):1972-1980

Wang C-C, Tsou C-L (1998) Enzymes as chaperones and chaperones as enzymes. FEBS Lett 425(3):382-384

Wilkerson VA (1935) The chemistry of human epidermis. J Biol Chem 112:329-359

Wilkinson B, Gilbert HF (2004) Protein disulphide isomerase. Biochim Biophys Acta 1699(1-2):35-44

Wilson RH, Lewis HB (1927) The cystine content of hair and other epidermal tissues. J Biol Chem 73(2):543-553

Wolfram LJ (2003) Human hair: A unique physicochemical composite. J Am Acad Dermatol 48:S106-S114

Wysocki AP, Mann GV, Stare FJ (1954) The cystine and methionine content of the hair of malnourished children. Am J Clin Nutr 2 (4):243-245

Xiao R, Lundstrom-Ljung J, Holmgren A, Gilbert HF (2005) Catalysis of thiol/disulphide Exchange: glutaredoxin 1 and proteindisulphide isomerase use different mechanisms to enhance oxidase and reductase activities. J Biol Chem 280(22):21099 21106. doi:10.1074/jbc.M411476200

Zviak C, Milléquant J (2005) Hair bleaching. In: Bouilon C, Wilkinson J (eds) The science of hair care, 2nd edn. CRC, Boca Raton, pp 246-268 